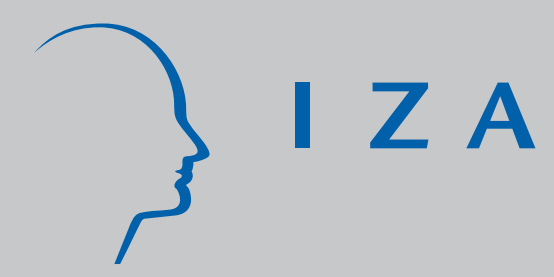

IZA DP No. 4008

Firm Recruitment Behaviour:

Sequential or Non-Sequential Search?

J os van Ommeren

Giovanni Russo

February 2009 


\title{
Firm Recruitment Behaviour: Sequential or Non-Sequential Search?
}

\author{
Jos van Ommeren \\ Free University Amsterdam \\ and Tinbergen Institute
}

Giovanni Russo

Free University Amsterdam

and IZA

\section{Discussion Paper No. 4008 \\ February 2009}

\author{
IZA \\ P.O. Box 7240 \\ 53072 Bonn \\ Germany \\ Phone: +49-228-3894-0 \\ Fax: +49-228-3894-180 \\ E-mail: iza@iza.org
}

\begin{abstract}
Any opinions expressed here are those of the author(s) and not those of IZA. Research published in this series may include views on policy, but the institute itself takes no institutional policy positions.

The Institute for the Study of Labor (IZA) in Bonn is a local and virtual international research center and a place of communication between science, politics and business. IZA is an independent nonprofit organization supported by Deutsche Post Foundation. The center is associated with the University of Bonn and offers a stimulating research environment through its international network, workshops and conferences, data service, project support, research visits and doctoral program. IZA engages in (i) original and internationally competitive research in all fields of labor economics, (ii) development of policy concepts, and (iii) dissemination of research results and concepts to the interested public.
\end{abstract}

IZA Discussion Papers often represent preliminary work and are circulated to encourage discussion. Citation of such a paper should account for its provisional character. A revised version may be available directly from the author. 
IZA Discussion Paper No. 4008

February 2009

\section{ABSTRACT Firm Recruitment Behaviour:
Sequential or Non-Sequential Search?*}

In the extensive job search literature, studies assume either sequential or non-sequential search. Which assumption is more reasonable? This paper introduces a novel method to test the hypothesis that firms search sequentially based on the relationship between the number of (rejected) job applicants and the number of employees hired. We use data compiled from filled vacancies for the Netherlands. Different types of search methods are distinguished. Our results imply that when firms use advertising, private or public employment agencies, which together cover about 45 percent of filled vacancies, sequential search is rejected. For about 55 percent of filled vacancies however, sequential search cannot be rejected. In line with theoretical considerations, when firms use search methods that rely on social networks, sequential search cannot be rejected.

JEL Classification: $\quad$ J63

Keywords: sequential search, recruitment

Corresponding author:

Jos van Ommeren

FEWEB

Free University Amsterdam

De Boelelaan 1105

1081 HV Amsterdam

The Netherlands

E-mail: jommeren@feweb.vu.nl

\footnotetext{
* We would like to thank Knut Roed for helpful comments and Marcel Hoogzaad for excellent assistance. Jos van Ommeren would like to thank the Frisch Centre, Oslo, Norway, for its hospitality. The authors are indebted to Lou Schreurs of Intomart b.v., in Hilversum (NL), for the use of the data. The usual disclaimer applies.
} 


\section{Introduction}

In the last few decades, search theory has become one of the main theoretical contributions to understanding the functioning of the labour market (see Devine and Kiefer, 1993). The theoretical and empirical search literature is enormous. Initially, the main focus of search theory was on the consequences of search behaviour by (unemployed) workers, whereas firm search behaviour received relatively less attention (early exceptions include Barron et al., 1985, Barron and Bishop, 1985). However, as search theory has changed its focus from onesided / partial search models (e.g., McKenna, 1985) to equilibrium search models that include search by (unemployed) workers as well as firms (see Burdett and Mortensen, 1998; Pissarides, 2000), search behaviour by firms has become more fundamental to search theory.

In this literature, the distinction between sequential and non-sequential search is fundamental. Most of the literature assumes that firms search sequentially for employees (see, for example, Mortensen, 2003). When searching sequentially, a firm screens each applicant immediately upon arrival, offers a job to the applicant when the productivity of the job applicant exceeds a certain threshold (the reservation productivity) and discontinues the search process if the job offer is accepted (Burdett and Cunningham, 1998). The most general way of defining non-sequential search is by contrasting it with sequential search, but, usually, the more narrow definition, as applied by Stigler (1961), is that with non-sequential search, a firm pools a number of applicants, screens the applicants, and offers the job to the best applicant in the pool of screened applicants. The main aim of the current paper is to test whether firms search sequentially or non-sequentially. Another aim is to classify different search methods used by firm as sequential or nonsequential.

It has been known for some time that (depending on the circumstances) each of these two search strategies may be optimal (e.g., Morgan, 1983; McKenna, 1985). ${ }^{1}$ For example, if screening applicants is expensive, if the applicants' arrival rate is low, or if there are no economies of scale in screening, then sequential search is more appropriate. On the other hand, non-sequential hiring may be preferred, if the job arrival rate is high: most job applicants apply within a certain short period, they can be cheaply examined (e.g., via prescreening), and the costs of posting a vacancy are sunk (which is the case with an advertisement). Since the aforementioned considerations are likely to affect the choice of

\footnotetext{
${ }^{1}$ The sequential search strategy and the non-sequential strategy, as introduced by Stigler (1961), are encompassed by the variable-sample-size strategy, which allows the firm to select an optimal pool of applicants, but to continue searching if the productivity of the best applicant in the pool does not exceed a certain threshold value (see, e.g., Morgan, 1983). In a case where the optimal pool size equals one, the variable-sample-size strategy is the sequential search strategy.
} 
search method, the search strategy adopted is likely to be contingent on the search method used, which, in turn, affects the arrival rate of applicants.

On the one hand, sequential search may be regarded as just an auxiliary assumption of search theory, whose purpose is to simplify the mathematics (for convenience only). On the other hand, in the more recent literature of structural equilibrium search models, the firms' sequential search assumption is one of the key assumptions through which these models are currently identified (see e.g., Mortensen, 2003, Van den Berg and Ridder, 1998; Cahuc et al., 2006). ${ }^{2}$ Hence, this poses the question as to what extent the sequential search assumption is a reasonable assumption.

Knowledge about search behaviour of firms is not only useful for proper modelling of the labour market, but it has been argued that it also affects government policies regarding unemployment and vacancies (Gautier, 2002; Albrecht et al., 2003; Albrecht et al., 2006). When firms and job seekers search sequentially, the labour market is characterized by search frictions arising from a coordination failure: some vacancies that could be productively filled are left vacant and, at the same time, some workers are unemployed. The job seekers' application period does not depend of the number of applicants. In this framework, posting a new vacancy has the usual congestion and thick market effects: on the one hand, it makes it harder for vacancies to find workers but, on the other hand, it makes it easier for workers to find a vacancy. Vacancy creation, however, affects the wage in such a way that the two aforementioned effects may be balanced by wage movements, and efficiency is thus attained (Hosios, 1990).

When firms search non-sequentially, the application period depends on the number of applicants to be screened and selected. From the applicant's point of view, this is equivalent to waiting in a queue, so each application creates a negative externality. Hence, this may imply that job seekers will apply to more vacancies at the same time than would be optimal without this externality. Furthermore, job applicants could use multiple job offers to make firms compete against one another, so that the applicants receive higher wages (Rynes et al.,

\footnotetext{
${ }^{2}$ For example, in structural equilibrium search models based on Burdett and Mortensen (1998), the wage is not assumed to be equal to the employer's (marginal) productivity, as would occur in the model without search frictions, but it is assumed that there exists a wage distribution and a wage offer distribution which are both a function of structural search parameters (e.g. the employees' job quitting rate) and the firm's productivity. The functional forms of these distributions are determined by the search technology of jobseekers and firms. One attractive assumption in this context is to assume that firms search sequentially. In principle however, it is also possible to allow for non-sequential search by assuming that each employer contacts a finite number of workers at a random in each period and chooses the best worker. This model encompasses the sequential search model as a special case (Mortensen, 2003, page 36).
} 
1991). Multiple job applications imply that job seekers search non-sequentially, so multiple applications are just the job seekers equivalent of firm non-sequential search. ${ }^{3}$ So, this makes it plausible that job seekers would respond to firms' non-sequential search procedures by adopting a non-sequential search strategy themselves (Morgan and Manning, 1985; Black and Loewenstein, 2002; Gautier, 2002). In other words, job seekers will apply to several vacancies for which they will be the preferred candidate. By applying to several vacancies, workers impose an externality on firms, because they may select an applicant who could eventually be hired by a competing firm (Albrecht et al., 2003). This behaviour brings about a loss of efficiency, however, because an increase in the number of vacancies will not generate the same number of matches in the economy (Albrecht et al., 2006). Hence, it has been argued in this literature that, given non-sequential search by firms, government intervention (through labour market policies) may effectively reduce the negative externalities described above.

Non-sequential search behaviour by firms is also closely related to the stock-flow matching literature (e.g. Coles and Smith (1998), Coles and Muthoo (1998), Coles (1999) and Coles and Petrongolo (2008)). For example, Coles and Petrongolo (2008) develop a test whether aggregate matching is consistent with unemployment being mainly due to search frictions (randomly matching) or due to job queues (stock-flow matching). Their findings favour stock-flow matching, which suggests the presence of non-sequential search (but does not exclude the presence of sequential search for a positive share of the matches).

The above considerations indicate that the difference between sequential and nonsequential search by firms is essential. ${ }^{4}$ However, despite a voluminous literature on job matching and organisational behaviour in the labour markets, we have much less information about employers' search strategies than we do about job seekers' search strategies (see, e.g., DeVaro, 2005). We are familiar with only a small number of studies that aim to distinguish between sequential or non-sequential search by firms. These studies, with the exception of Abbring and Van Ours (1994), employ information on the vacancy duration. In these studies, it is argued that when the arrival rate if applicants is initially high, and then drops during the vacancy duration, and the acceptance rate is initially low and then rises, vacancy duration

\footnotetext{
${ }^{3}$ See, among others, Burda and Profit (1996) and Lang and Majumbar (2004). In these studies, nonsequential search by workers is assumed, and the economic consequences of this assumption are studied.

${ }^{4}$ Information about whether firms use sequential or non-sequential search is also instrumental to the empirical analysis of vacancy durations, as stressed in Burdett and Cunningham (1998) and Coles and Smith (1998).
} 
seems to be mostly driven by screening and selection in non-sequential search (rather than waiting time in sequential search).

Van Ours and Ridder (1992, 1993) and Abbring and Van Ours (1994) conclude that firms search non-sequentially, and that vacancy durations are essentially selection periods. In contrast, Burdett and Cunningham (1998) and Andrews et al. (2008), who analyse vacancy durations using public agency data, conclude that it is more likely that the majority of firms have used sequential search, as most vacancy durations are so short that most job applicants arrive and are accepted almost immediately.

As noted by Andrews et al. (2008) though, interpretation of the above studies is not clear cut because a short vacancy duration does not rule out non-sequential search. When most firms recruit workers rather quickly after opening a vacancy, then this is evidence of a short screening procedure only. So, it is difficult to accept a short vacancy duration as evidence for sequential search. Another issue is that these studies do not quantify which proportion of job matches in the economy are filled using non-sequential search.

In the above-mentioned studies, the choice of the specific search method, such as advertising, public agency, temporary agency, etc., is not made explicit. In these studies, either the search method is not observed (e.g., Van Ours and Ridder, 1992, 1993; Burdett and Cunningham, 1998), or the data analysed are based on observations from one search method only (e.g., Abbring and Van Ours, 1994; Andrews et al., 2007). Hence, these studies do not relate their results to the recruitment literature, which focuses on differences between search methods (see Roper, 1988; DeVaro, 2005). This literature, however, suggests a strong relationship between search method and type of search behaviour (sequential versus nonsequential search), see Andrews et al. (2007), but this relationship has neither been taken into account nor formally tested.

Since Rees (1966), it has become common to distinguish between formal and informal employer search methods. ${ }^{5}$ Informal search methods include walk-ins (sometimes referred to as "open applications"), asking current personnel and business relations for referrals, and searching internally within the firm. Formal search methods include advertisements and the use of different types of employment agencies (temporary, public or private).

A priori, one expects that informal search methods likely imply sequential search, since these methods do not involve large sunk costs, and imply a rather low applicants' arrival

\footnotetext{
${ }^{5}$ This distinction is generally regarded as useful since informal search networks use embedded social networks to provide additional information on applicants (Montgomery, 1992), which then may be used to attract more productive applicants.
} 
rate (Montgomery, 1992). In contrast, in the case of job advertising (a formal search method), studies argue that non-sequential search is optimal, since the costs of advertising are upfront and therefore sunk (Morgan, 1983; McKenna, 1985). When an employment agency is used, both types of search methods seem plausible. ${ }^{6}$

The main insight of our paper is to consider the relationship between the number of (rejected) applicants and the number of vacancies as being indicative of the search strategy adopted by firms: sequential or non-sequential. To be more precise, when firms search sequentially, then the number of (rejected) applicants must be proportional to the number of filled vacancies. Arguably, an analysis that focuses on the number of (rejected) applicants as the dependent variable, instead of the vacancy duration, as has been common in the previous literature, has as an advantage, in that it tests the basic statistical properties of the sequential search process. ${ }^{7}$

The main contribution of the current paper is to test empirically whether firms search sequentially. Our empirical analysis is novel in two respects: first, by using the proportionality between the number of filled vacancies and the number of (rejected) applicants that arise when firms search sequentially, we are able to test explicitly for sequential search; second, the analysis is based on a large and rich dataset of filled vacancies, which allows us to distinguish between ten different search methods. ${ }^{8}$ Hence, we are able to test for sequential search by distinguishing between different search methods. As we distinguish between a large number of different search methods, it also enables us to quantify the presence of non-sequential search, an important issue which has not been adequately addressed before. ${ }^{9}$

\footnotetext{
${ }^{6}$ For example, one may argue that given the use of private employment agencies, the type of search may depend on whether the firm pays a fixed fee to the agency. In the case of a fixed fee (e.g., a fee equal to two month's wages of the accepted applicant), non-sequential search is more likely to be preferred; in the case of a fee per applicant, sequential search is more likely to occur.

${ }^{7}$ Our approach does not rely on any auxiliary assumptions about the time-length of the selection process, such as in the literature that analyses vacancy durations. For example, firms that recruit through a public employment agency, tend to fill their vacancy rather quickly. This has been interpreted as an indication that firms search sequentially (see Andrews et al. (2008). However, it is equally plausible that firms receive a pool of applicants through the employment agency, so they search non-sequentially, and recruit after a short, selection period.

${ }^{8}$ Use of the test we introduce is not limited to the labour market, for it fits within the substantial theoretical and empirical literature on sequential decision-making applied to product search (see Zwick et al. (2003), for a recent contribution to the consumer search literature). For example, in the case of an Internet search, sequential search would imply a proportional relationship between the number of (nearly identical) items purchased and the number of (Internet) locations visited.

${ }^{9}$ The previous literature, as discussed above, either does not distinguish between methods (e.g. Van Ours and Ridder, 1992), or is based on one type of search method (e.g. Burdett and Cunningham, 1998).
} 
Our results imply that for seven out of ten search methods - including the informal recruitment methods that rely on social networks - we are not able to reject sequential search. For the remaining three search methods (advertisements, private and public employment agencies), the hypothesis of sequential search is rejected. In the Netherlands, as has been noted by Van Ours and Ridder (1992), the incidence of advertising is substantial. However, the incidence of public employment agencies is also substantial. In fact, the combined use of advertising and public and private employment agencies covers $45 \%$ of the vacancies. Hence, for $45 \%$ of the vacancies, and therefore of successful applications, firms use non-sequential search. ${ }^{10}$ Our data do not allow us to determine the proportion of job seekers who may be confronted with a non-sequential search strategy by firms (and therefore may turn to a nonsequential search strategy themselves, see, e.g., Morgan and Manning, 1985; Black and Loewenstein, 2002; Gautier, 2002), but it indicates that, at least in the Netherlands, a substantial proportion of job seekers are confronted with non-sequential search by employers, in at least one of their applications. ${ }^{11}$

The paper proceeds as follows: the next section offers a theoretical model, to derive the relationship between the number of (rejected) applicants and the number of vacancies. Section three describes the data, and provides the results from the empirical analysis. Section four concludes.

\section{Theory}

Consider a firm with $v$ identical job openings in a stationary environment $(v \geq 1) .{ }^{12}$ To attract job applicants, the firm chooses between two (types of) search methods: one method implies sequential search, the other method implies non-sequential search. ${ }^{13}$ Upon arrival of the job applicants, the firm has to determine the productivity level, $X$, of the applicants, by screening

\footnotetext{
${ }^{10}$ This finding will be shown to hold for subgroups of workers, including groups of workers with different educational levels. Workers with a university degree tend to apply for advertised jobs, and are therefore confronted with a non-sequential search strategy by firms, whereas workers with only basic education tend to use public employment agencies, and are therefore also confronted with nonsequential search strategies by firms.

11 This suggests, however, that sequential search may be a fairly good approximation of firms' recruitment behaviour in countries where the use of informal search methods is more common (such as in Italy and the United States). In countries where advertising and public employment services are frequently used, non-sequential search will be quite common, however.

${ }^{12}$ Stationarity is in line with the literature. For example, Van Ours and Ridder (1991) show that the reservation productivity does not fall over time.

${ }^{13}$ This assumption is strongly supported by our data. We are able to identify sequential and nonsequential search methods. We have then examined what proportion of recruitment actions used both
} 
the applicants. Before screening, the firm does not know their level of productivity. The firm knows only the cumulative productivity distribution of applicants, $F(X)$. The screening of applicants is costly, and screening costs, $c$, are fixed, for each applicant. The productivity distribution function, $F(X)$, and $c$ may differ between these two search methods. ${ }^{14}$ Applicants who receive a job offer from the firm will always accept the job offer. ${ }^{15}$

Now assume that it is optimal for a firm to use a search method such that applicants are sequentially screened. The probability of hiring an applicant then depends on the level of the reservation productivity, $X^{R}$, which is optimally set by the firm. The average number of applicants to be screened before the firm finds one additional, suitable applicant is equal to $1 /\left(1-F\left(X^{R}\right)\right)$. For $v$ vacancies, the total number of applicants screened is denoted as $n$. Given sequential search, the firm will screen one applicant each period until the number of suitable applicants equals the number of job openings. Assume now that the reservation productivity does not depend on the number of vacancies. Given this productivity independence assumption, a firm that tries to fill $v$ vacancies in sequential order behaves then as if it is attempting to fill a single vacancy $v$ times ( $v$ search actions).

The productivity independence assumption is essential here, but we believe it is reasonable: it is unlikely that firms will open an additional vacancy if they anticipate that this will induce them to reduce the reservation productivity (see, also, Akerlof, 1981), because it will, at least theoretically, be more economical to wait between the openings of vacancies. ${ }^{16}$ Hence, if the reservation productivity does fall for certain firms, multiple identical vacancies should not be observed for those firms. ${ }^{17}$ We will proceed by maintaining the independence

search methods. In only $12 \%$ of all observations are both a sequential and a non-sequential search method used.

${ }^{14}$ There is a substantial literature that argues that $F(X)$ for informal methods stochastically dominates the $F(X)$ for formal search methods, so for informal search methods, the expected productivity level of applicants is higher than for formal search methods (Montgomery, 1992). Further, the screening costs are thought to be lower for informal search methods than for formal search methods, as firms have more a priori information about applicants.

${ }^{15}$ The assumption that the applicants who receive a job offer from the firm will always accept the job offer can be easily relaxed by the assumption that the probability that the job offer will be rejected is independent of the number of vacancies. We believe that the latter assumption is more reasonable, but keep the former assumption for expositional reasons.

${ }^{16}$ Strictly speaking, Akerlof (1981) argues only that the effect of the arrival rate of applicants on the reservation productivity may be limited, when firms set a rock-bottom reservation productivity to prevent underutilization of the vacant position, but this argument can also be used for the number of vacancies, since the number of vacancies presumably affect the reservation productivity, through the arrival rate.

${ }^{17}$ Let us give two polar examples. In a standard call-centre job, it is unlikely that reservation productivity depends on whether one or multiple vacancies are available. Therefore, multiple vacancies will be used when needed. In universities, for positions calling for specialized scientists, and 
assumption, but the consequences of relaxing this assumption will be explored in detail later, in Section 3.3. We will show that relaxing this assumption will not affect our qualitative conclusions. Furthermore, we will test, and reject, that productivity is a negative function of the number of vacancies supporting the productivity independence assumption.

Given these assumptions, the number of rejected applicants, denoted as $n^{r}$, will follow the well-known negative binomial distribution (see, e.g., Mood et al., 1974), which is popular in the estimation of count models (e.g., Winkelmann, 2003). A random variable $n^{r}$ is defined to have a negative binomial distribution if the density of $n^{r}$ is given by $\left(\begin{array}{c}v+n^{r}-1 \\ n^{r}\end{array}\right)\left[1-F\left(X^{R}\right)\right]^{v} F\left(X^{R}\right)^{n^{r}}$. The expected value of $n^{r}, E\left(n^{r}\right)$, equals then $v F\left(X^{R}\right) /(1$ $F\left(X^{R}\right)$ ). The negative binomial distribution describes the distribution of the number of failures that will occur before exactly $v$ successes have occurred in an infinite sequence of Bernoulli trials with probability $1-F\left(X^{R}\right)$ (for $v=1$, this distribution reduces to the geometric distribution). For this distribution, the expected number of rejected applicants, $E\left(n^{r}\right)$, is proportional to the number of vacancies. Hence, our test of sequential search is simply to test whether the expected number of rejected applicants is proportional to the number of vacancies. This result is intuitive, because given sequential search, the number of rejected applicants per vacancy does not depend on screening behaviour for the other vacancies. In conclusion, given sequential search, the vacancy elasticity, $\gamma$, defined here as the elasticity of the number of rejected applicants with respect to the number of vacancies, is equal to one. ${ }^{18}$

Now assume that it is optimal for firms to use a search method which implies that they will screen non-sequentially. Firms then gather a pool of applicants, $n$, of which the size is optimally chosen before the screening process begins (e.g., Morgan, 1983). ${ }^{19}$ For now, suppose that all applicants in the pool are screened, and the firm will hire the $v$ most-

for which the arrival rate is usually quite low, it is rare that a large number of vacancies will be filled within a short period, instead the filling of vacancies will be spread over time.

${ }^{18}$ The number of applicants, $n$, is equal to the sum of the number of rejected and accepted applicants, $n^{a}$. It follows that if the expected number of rejected applicants is proportional to the number of vacancies, the expected number of applicants, $n$, is also proportional to the number of vacancies. This is a trivial result. Note that when $E\left(n^{r}\right)=\theta v$, then $E(n)=(\theta+1) v$. Therefore, for the purpose of the current paper, it is rather arbitrary if one analyses the effect of the number of vacancies on the total number of applicants, $n$, or on the number of rejected applicants. In our main empirical analysis, which relies on count data analysis, we will analyse the number of rejected applicants, whereas in the sensitivity analysis, where we also make use of regression analysis, we will analyse the total number of applicants.

${ }^{19}$ Our analysis is related to statistical issues in the field of genetics. In this field, one aims to know the average score of a selected group of top scorers of size $v$ of a large group with size $n$, which is compared to the average score in the population (e.g., Burrows, 1972; David, 1981). 
productive workers. The optimally-chosen number of applicants is determined by the usual condition that the marginal costs of screening are equal to the marginal benefits of filling the job opening. In this case, the vacancy elasticity is not necessarily a constant that is equal to one. Furthermore, the vacancy elasticity, $\gamma$, may be a function of the number of the vacancies, $v$. Consequently, the null hypothesis - that firms recruit sequentially - can be tested by testing whether $\gamma$ is equal to one. If $\gamma$ is not equal to one, then firms do not search sequentially. ${ }^{20}$

A necessary condition for sequential search is that the vacancy elasticity is equal to one. This result is independent of the productivity distribution, $F(X)$. This raises the question whether this condition is a sufficient condition. In other words, we ask if there exists at least one productivity distribution that, given non-sequential search, will yield a unit vacancy elasticity. In Appendix 1, it is shown that given non-sequential search, as defined by Stigler (when employers pool the number of applicants, where the number of applicants is optimally chosen and the most productive applicants are chosen), such a distribution exists. ${ }^{21}$ When the productivity distribution follows an exponential distribution, then the vacancy elasticity is a unit, given non-sequential search. Hence, $\gamma$ equals one is a necessary, but not a sufficient, condition for sequential search. It is possible to come up with other examples of nonsequential search where the vacancy elasticity is equal to one. ${ }^{22}$ Hence, the unit elasticity test we propose, to discriminate between sequential and non-sequential search, must be regarded

\footnotetext{
${ }^{20}$ In the current paper, we test for sequential search by investigating the effect of the number of vacancies on the average number of rejected applicants, but one may wonder if it is not possible to apply a test based on the effect of the number of vacancies on the distribution of the number of rejected applicants. The answer is yes, if one is prepared to make restrictive assumptions about unobserved heterogeneity. Otherwise, the answer is no, as unobserved heterogeneity affects the second moment of count data and therefore the distribution.

${ }^{21}$ Note that the seminal study by Stigler (1961) restricts the number of vacancies to one, whereas in the current study we allow for multiple vacancies.

${ }^{22}$ An alternative non-sequential search strategy may be to announce a deadline (which is the typical scenario for job ads). If the probability for each single job seeker to apply for a job is proportional to the number of positions available, the proportionality result emerges. Note further that in the sequential search model, it is assumed that all rejected applicants are screened at a given marginal cost. However, one alternative non-sequential search strategy is to pool a number of applicants and immediately reject a certain share of the applicants based on a screening procedure, which is essentially costless, and then to screen sequentially the remaining applicants. This may be feasible when firms employ screening procedures based on written application letters). If none of the applicants in the pool is accepted, repeat the search strategy by forming a new pool until an acceptable applicant is found (see Morgan, 1983). This strategy may be realistic for certain search methods, such as advertising, where the cost of attracting applicants is fixed, but the actual number of applicants may exceed the optimal number. Now, suppose that the share of immediately rejected applicants does not depend on the number of vacancies, so this share is essentially fixed. In this special case of nonsequential search, the vacancy elasticity is also equal to one.
} 
as a conservative test. It is theoretically possible that the test does not reject sequential search, when firms do search non-sequentially.

In the empirical application, we will test for a unit-elasticity. Intuition suggests that, given non-sequential search, the vacancy elasticity is strictly less than one, so the alternative hypothesis is more specific. ${ }^{23}$ Let us give an example for which we can formally demonstrate this intuition. Suppose that the productivity distribution is uniform and the number of applicants, $n$, is continuous. Suppose a firm pools a number of applicants, screens the applicants, and offers the job to the best applicant in the pool of screened applicants. The optimal number of applicants is then an increasing concave function of the number of job openings. If the screening cost is low, relative to the value of a filled vacancy - a condition that almost certainly will be met - then $\gamma=(2 v+1) /(2 v+2)<1 .{ }^{24}$ See Appendix 1 for a formal proof. This implies that given non-sequential search, $\gamma$ is a function of $v$, and $\gamma<1$ for any value of $v$. Only when the number of vacancies is (infinitely) large, does $\gamma$ approach a constant equal to one. ${ }^{25}$

\section{Data and results}

\subsection{The data and descriptive analysis}

The data used in the empirical analysis were derived from a survey on the search behaviour of Dutch establishments entitled, "How do firms recruit?" (HDFR, 1998). In the current paper, establishments will be called firms, in line with the terminology of the theoretical model. The survey was carried out by telephone, every two months during the period between 1991 and 1998. ${ }^{26}$ The data do not have a panel structure, because a new random sample of firms was drawn each time. To begin with, firms were asked to report on their total hiring activity during the past year (the aggregate number of filled vacancies).

\footnotetext{
${ }^{23}$ Suppose a firm aims to fill one vacancy, gathers an optimal pool of $n$ applicants, and chooses the most productive applicant, and the other $n-1$ applicants are rejected. If the firm now aims to fill two vacancies, then the optimal size of the pool will be less than $2 n$, because one of the rejected applicants for the first vacancy may be acceptable for the second vacancy.

${ }^{24}$ This result implies, of course, a negative relationship between the number of vacancies and the number of applicants per vacancy.

${ }^{25}$ Note that the test will be applied conditional on the chosen search method. This is a valid procedure, because we do not estimate the effect of the choice of a certain method on the likelihood that firms search sequentially, but we show that the choice of a certain method reflects sequential or nonsequential search behaviour.

${ }^{26}$ The dataset covers a period of eight years, starting in 1991, which was a period of a slack labour market (a recession would follow in 1993 and 1994), and terminating in 1998, a year characterised by a very tight labour market due to three years of continuous employment growth.
} 
The survey records all recruitment actions concluded by the firm in the two months prior to the interview. Information is gathered regarding occupational codes, job descriptions, and functions. One of these recruitment actions was then randomly selected, using a pseudorandom generator procedure, as the focus of an in-depth interview. So, the interview focused only on one recruitment action that took place during the two months prior to the interview. During the interview, additional information is gathered about this particular recruitment action only. This paper analyses information obtained from this interview.

For the (randomly-selected) recruitment action, the survey provides information on many elements of the search process, such as the number of applications received, and the search methods used. A recruitment action may involve the filling of multiple identical vacancies (see, similarly, Barron and Bishop, 1985; Andrews et al., 2008). ${ }^{27}$ By construction, identical vacancies share the same four digit occupational code, job description and function. $^{28}$ Moreover, detailed background information on both firm and vacancy characteristics (such as the educational level or work experience requirements, the presence of maximum age limits, whether it concerned a part-time position, and whether it concerned a permanent contract) are also provided (for summary statistics, see Appendix 2).

In the theoretical and empirical analysis, we focus on filled vacancies, which potentially differ from the vacancies to be filled (Andrews et al., 2008). The analysis may generate biased estimates of the coefficients of interest, if the reported number of applicants relates not only to the vacancies that are filled but also to vacancies that are cancelled. For the Netherlands, the proportion of vacancies cancelled is only 4\% (Van Ours and Ridder, 1992), so any bias in the estimates will be negligible so we will ignore this issue.

Firms may use multiple search methods during the hiring procedure, sequentially or simultaneously (Roper, 1988). Our analysis distinguishes search activities by the firstemployed search method, which is predominantly the only search method used. Most firms usually limit themselves to a single search method: in $82 \%$ of the cases (of randomly-selected hiring activities) only one search method was used (such a high percentage is consistent with studies for Belgium and the U.K., but not for the U.S., where multiple search methods are

\footnotetext{
${ }^{27}$ The question used in the survey about the number of identical vacancies reads as follows: "How many vacancies (of the selected type) have been filled during the (selected) recruitment action?"

${ }^{28}$ One cannot completely exclude the possibility that some vacancies that are reported to be identical differ in some aspects. In particular, the expected means of the number of (rejected) applicants may differ between the different vacancies belonging to the same recruitment action (for example, one may imagine that a university aims to attract two labour economists, one with a theoretical and the other with an empirical background; the expected number of applicants may differ between these two
} 
more common). The frequency distribution of search methods is given in the first column of Table 1 (the second column repeats the result when only one search method is used). The third and fourth columns represent the frequency distribution of search methods, weighting the observations by the number of vacancies filled and by the number of applications received.

Table 1 shows that the data cover 39,814 firms (hiring activities or recruitment actions) involving 100,043 vacancies and 609,263 applications. To avoid the confounding effect of mixed recruitment strategies (those using more than one recruitment method), in this section, we focus on the selected sample of 32,546 recruitment actions that used one recruitment method exclusively (the multivariate analysis is conducted on the selected, as well as the whole, sample). These firms filled 70,730 vacancies and received 450,858 applications. $^{29}$

\section{Table 1 ABOUT HERE}

In Table 1, the top four search methods are labelled "informal search methods," whereas the remaining methods are referred to as "formal search methods" (Rees, 1966). The residual category, "Other search methods," includes a combination of less common methods such as Internet recruiting. ${ }^{30}$

Under the hypothesis of sequential search, the average number of applicants is proportional to the number of vacancies. The average number of applicants per filled vacancy should then remain constant, regardless of the number of vacancies filled. The average number of applicants per vacancy by search method, when 1, 2, 3, and 4 vacancies are filled, is shown in Table 2; the last column contains the average number of applicants per filled vacancy (across search methods). ${ }^{31}$ On average, about nine applications per vacancy are received, in line with the literature (for example, Barron and Bishop, 1985, report exactly the same number for the United States). There is substantial variation in the average number of

vacancies). This does not affect our test however, because sequential search still implies that the expected total number of rejected applicants is proportional to the number of vacancies.

${ }^{29}$ For example, Table 1 shows that, in the whole sample, 28\% of the recruitment actions relied on advertising. In the restricted sample (restricted to those recruitment actions that made use of one search method only), $29 \%$ of the recruitment actions and $32 \%$ of all vacancies used advertisements. Because advertisements tend to provide a large flow of applicants, $68 \%$ of all job applications have been involved in a recruitment action that used advertisements only.

${ }^{30}$ Note that our sample refers to a period when Internet recruitment was still very rare.

${ }^{31}$ In about $90 \%$ of the cases, fewer than five vacancies were filled; the table is therefore quite representative. 
applicants per vacancy, across search methods. The use of advertising results in a significantly higher number of applicants per vacancy (about 21). The use of business relations and school search imply, on average, a particularly low number of applicants per vacancy (about 2).

\section{Table 2 ABOUT HERE}

Table 2 offers prima facie evidence that contradicts the hypothesis of sequential hiring, for some search methods. In particular, for three formal search methods (advertising, public and private employment agencies), the average number of applicants falls strongly, as the number of filled vacancies increases. However, sequential hiring seems to hold much better, for the informal search methods.

\subsection{Main empirical results}

We aim to classify different search methods as being sequential or a nonsequential. According to theory, the type of search strategy is closely related to the type of search method used, justifying our choice to estimate the vacancy elasticity for each search method separately. Because a limited number of vacancies employ more than one search method, we distinguish between subgroups based on the first search method employed. ${ }^{32}$ The dependent variable, the number of rejected applicants, will be treated as count data. In line with theory, we use a (generalised version of the) negative binomial regression model. ${ }^{33}$

One of the potential disadvantages of the count model approach (compared to, e.g., a regression approach) is the implicit assumption that the dependent variable is observed without measurement error. When the count variable is observed with measurement error, then the estimates will be biased (in an unknown direction, see Winkelman, 2003). The frequency distribution of the number of rejected applicants indicates that if the number of applicants exceeds about 15 , then the number of rejected applicants is rounded to multiples of 5, 10 and 50 (e.g., 25 occurs much more frequently than does 24 or 26). To account for this peculiarity, we have right-censored all observations that received more than 20 applicants per vacancy. This affects only $2.45 \%$ of the sample, so losses in efficiency are small. Another advantage of this approach is that a small number of potential “outliers” (e.g., observations

\footnotetext{
${ }^{32}$ An analysis of vacancies that use only one search method generates almost identical results.

33 The model corresponds to the negative binomial model NB2 (Cameron and Trivedi, 1998). Estimation is done via Maximum Likelihood, using Stata.
} 
with hundreds of applicants) do not drive the results. We have also experimented with other threshold points, to right-censor the data (e.g., more than 10 applicants, which refers to 11\% of the sample), but the results remain robust.

The negative binomial model requires the specification of the conditional mean, $\mu$. We specify $\mu=\exp (\beta X+\gamma \log v)$, where $\mathrm{X}$ is a vector of exogenous regressors, $\gamma$ is the vacancy elasticity, and $\beta$ is a vector of parameters to be estimated (Hilbe, 2007). Moreover, a parameter, $\alpha,-$ a dispersion parameter - has to be specified, which may depend on explanatory regressors. We specify $\alpha=\exp \left(\sigma_{1}+\sigma_{2} \log v\right)$, where $\sigma_{1}$ and $\sigma_{2}$ are parameters to be estimated, see e.g. Cameron and Trivedi (1998) and Hilbe (2007). Hence, in the estimates shown here, we allow $\alpha$ to depend on a constant, and on the logarithm of the number of vacancies (allowing for additional regressors generates almost identical results). Importantly, we will focus on the parameter $\gamma$ which captures the overall effect of vacancies on the mean number of rejected applicants.

The results, for each individual recruitment method, are presented in Table 3. The first row in the table contains the estimates of the main coefficient of interest, $\hat{\gamma}$. The test of sequential search amounts to testing whether this coefficient is statistically different from one.

Our main result is that sequential search is rejected when advertising, or the public and private employment agencies are used. Note that these three methods are all formal methods. The estimated vacancy elasticities are not only statistically different from one, but the size of the elasticity is much less than one. For these three methods, the elasticities are around 0.60 . Clearly, for these three methods, firms are able to economise on recruitment costs through non-sequential search. We can only speculate about the underlying causes as to why these three methods imply non-sequential search, but the low elasticity obtained for advertisements is likely due to the high, fixed-costs involved for this particular recruitment method. Only for one informal method, internal recruitment, is sequential search statistically rejected; but, the size of the coefficient, 0.88 , is so close to one that it suggests that the sequential search assumption may be a reasonable approximation. ${ }^{34}$ For the other search methods, sequential search is not rejected. Importantly, the estimated standard errors of the estimated coefficient of vacancy are rather small. Therefore, this result cannot be attributed to the lack of a sufficient number of observations.

\footnotetext{
${ }^{34}$ The results for the other explanatory variables are in line with the literature. For example, the number of (rejected) applicants is a positive function of the educational requirement, in line with the argument that the extensive cost of search will be higher for jobs with higher educational requirements (see, for example, Barron and Bishop, 1985).
} 


\section{Table 3 ABOUT HERE}

The three recruitment methods that imply non-sequential search cover $45 \%$ of the vacancies and $78 \%$ of the job applications (see Table 1 ). Since job seekers vary in the number of applications (the less successful ones will send out more applications), the number of job applications cannot be interpreted as equivalent to the number of job seekers. The results, however, can be interpreted to indicate that at least $45 \%$ of job applicants are involved in a non-sequential selection process before finding a job, but this proportion is likely (substantially) higher.

We have also investigated whether the above results hold for subgroups. For example, one may imagine that the type of educational requirement affects the screening costs or the arrival rate of candidates and therefore the choice between sequential or non-sequential methods. We have therefore repeated the analysis for the 10 different recruitment methods distinguishing now between subgroups defined by educational requirements. In one analysis, we split the sample in two subgroups based on the level of educational requirement (low versus high education); in another analysis, we split the sample in two groups using the type of educational requirement (vocational versus general education). In essence, the results do not change and the vacancy elasticity is about the same for each subgroup. ${ }^{35}$ For example, for advertising, the vacancy elasticity is estimated within the range of 0.44 and 0.49 for the low, high, vocational as well as the general education subgroup. ${ }^{36}$ The above test of sequential search tests only whether the vacancy elasticity is equal to one. One may argue that it may

\footnotetext{
${ }^{35}$ We have also examined whether this conclusion holds for different subgroups not distinguishing by recruitment method. For each vacancy, we know the previous labour market position, educational level, and work experience of the accepted applicant. Thus, we have estimated the same models as provided in Table 3, distinguishing now between different subgroups (but not between different recruitment methods). It appears that the estimated vacancy elasticity is hardly different for the different subgroups. The full results can be received upon request. These results can be more easily understood by focusing on the descriptives. It appears that the proportion of non-sequential search methods differs little by the defined subgroup (subgroups that tend to use advertising tend to avoid public employment agencies, see Appendix 3). Actually, highly-educated applicants are slightly more likely to be confronted with non-sequential search methods, as has been suggested in the literature (Lang and Majumdar, 2004).

${ }^{36}$ The only exception, where the size of the vacancy elasticity is fundamentally, and statistically, different from the main result discussed above is for firms that use temporary employment agencies and which recruit high-educated workers. In this case, the results indicate nonsequential search, whereas, above, we report sequential search given the use of temporary employment agencies. This result seems to make sense, and is in line with our finding that firms which use private employment agencies use nonsequential search cover as it is realised that for high education vacancies the distinction between temporary and private employment agencies may not always be so clear.
} 
useful to apply an alternative test, which not only tests whether the vacancy elasticity is equal to one, but also tests that the vacancy elasticity does not depend on the number of vacancies. To increase the statistical power of this test, we have pooled all observations that refer to the search methods identified above as being sequential (so we include all recruitment methods except advertising, public and private employment agencies). To apply the test, we have included vacancy dummy variables (instead of the logarithm of the number of vacancies), where one vacancy is the reference category. As the number of observations with more than four filled vacancies is limited, we have selected only observations with a maximum of four filled vacancies. To ease interpretation of the results, the three vacancy dummies do not take the values zero or one, which is common, but, instead, take the values zero or the logarithm of 2, 3 or 4, respectively. It appears that the vacancy elasticities for two, three and four vacancies are equal to 1.017 (0.059), 0.990 (0.052), 0.931 (0.053), respectively, where the standard errors are given in parentheses. Note that the estimates are very close to one, and very close to each other. More formally, the application of a standard likelihood ratio test of the assumption that the vacancy elasticity does not vary by number of vacancies and is equal to one shows that this assumption is not rejected. Consequently, sequential search is not rejected for these three search methods, using this alternative test.

\subsection{Sensitivity analysis}

We have investigated the robustness of our results by re-estimating the models on a selective sample, by controlling for a number of additional explanatory variables, as well as by applying alternative estimation methods than a count estimation approach, which arguably, in the current context, have some statistical merits.

\subsubsection{Recent recruitment experience}

We have also re-estimated the same models on a sample of firms that had filled at least one other vacancy during the previous year. These estimates are useful because firms with recent recruitment experience are most likely well informed about the state of the labour market, in line with the assumptions of the theoretical model, which requires that the productivity distribution of applicants is known to firms. For firms that did not recruit recently, this assumption may be less valid. The restricted sample contains 25,481 observations. Table 4 shows that given the selection, the parameter estimates (second row in Table 4) remain very close to those obtained when the whole sample was utilized (first row in Table 4). The only slight difference is that sequential search is not rejected when firms recruit internally (with a 
coefficient of 0.932 and a standard error of 0.053 ). This is consistent with our previous interpretation of the vacancy elasticity for internal recruitment, because the size of the estimated elasticity in the original estimate was close to one ( 0.884 with a standard error of $0.044)$.

TABLE 4 About here

\subsubsection{Additional explanatory variables}

One may argue that the omission of some variables, correlated with the number of filled vacancies, may potentially bias the estimated coefficients. In particular, for a given level of skill requirements (education, experience etc), unobserved skill level requirements may be correlated with the number of vacancies (to the extent that skilled jobs are less standardized, on average, a large number of vacancies may reflect low job skill content). If this is the case, then the estimated vacancy elasticities are downward biased, suggesting we reject sequential search too often.

Note that this argument is not too convincing, because we control for a large number of explanatory variables. More fundamentally, if this argument is valid then the estimated vacancy elasticities should be less than one across all types of search methods, which is not the case.

It is generally acknowledged that skill requirements are strongly correlated with wages and job turnover, so firms offering jobs with unobserved low skill requirements will be paying lower wages and will incur high turnover rates. If this is the case firms offering jobs with unobserved low skill requirements will be more likely to hire new personnel in the near future. Following this line of reasoning we have controlled for firms' job skill content by using the firms' intention to hire new personnel in the next two months. ${ }^{37}$ The effect of the introduction of firms' intentions to hire on the elasticity of the number of (rejected) applicants to the number of vacancies is shown in the third row in Table 4: we find that the inclusion of this additional variable does not alter any of the vacancy elasticities. ${ }^{38}$

\footnotetext{
${ }^{37}$ Firm's intention to hire in the two month is derived from the following question: "Do you intend to hire new personnel during the coming two months?” the answers were coded as a 4-point Likert scale going from 1 (certainly do) to 4 (absolutely not).

${ }^{38}$ Our preferred specification is without the additional future recruitment activities controls, because according to the theoretical model, these variables do not affect the relationship between the number of vacancies and the number of applicants. On the other hand, one may argue that these variables pick up unobserved recruitment requirements and should be included. As the results are identical with these
} 


\subsubsection{Alternative estimation methods}

We have shown that sequential search implies that the expected number of (rejected) applicants is proportional to the number of vacancies. Hence, it is also possible to test for this relationship using a regression analysis. Particularly, in the case of advertising, when, on average, 21 applicants apply, and, where for almost all vacancies, the number of applicants exceeds the number of vacancies, a regression analysis based on a specification in logarithms offers some advantages compared to a count model: regression analysis tends to be more robust than count model estimates, for example, with respect to underlying assumptions of measurement error in the dependent variable (see Winkelman, 2003). In fact, results using ordinary least squares (OLS) generate almost identical results as for the count model reported. Improving these estimates by taking into account that the number of applicants must exceed or be equal to the number of vacancies (Tobit models) does not affect this conclusion. We refer to Appendix 4 for more details.

\subsection{The productivity independence assumption}

Using arguments going back to Akerlof (1981), we have argued above that it is plausible that the reservation productivity does not depend on the number of vacancies. This implicitly assumes a proportional relationship between the applicants' arrival rate and the number of vacancies (hence, if the number of vacancies doubles so does the number of applicants, such that the reservation productivity remains unchanged). In other words, the matching technology at the firm level exhibits constant returns-to-scale in the number of identical vacancies to be filled. This matching technology is in line with studies such as Van Ours and Ridder (1991) which show that the reservation productivity does not fall over time. ${ }^{39}$

What happens nevertheless to our results if we allow the matching technology to be characterized by decreasing returns-to-scale at the firm level (i.e., the increase in the number of vacancies is matched by a less-than-proportional increase in the number of applicants) ${ }^{40}$ When this is the case, the reservation productivity $\mathrm{X}^{\mathrm{R}}$ falls, and the acceptance probability, 1-

additional controls, it is rather arbitrary which specification is the preferred one. The full set of results can be received upon request.

${ }^{39}$ Note that the constant-returns-to-scale assumption for identical vacancies (within the same firm) is a completely different concept than the constant-returns-to-scale assumption in the aggregate matching literature. The large empirical matching literature on aggregate data at the level of the (regional) economy is therefore not indicative whether the reservation productivity is a function of the number of identical vacancies within the firm. 
$\mathrm{F}\left(\mathrm{X}^{\mathrm{R}}\right)$, becomes a positive function of the number of vacancies posted. To see the consequences for our empirical tests, assume that $1-\mathrm{F}\left(\mathrm{X}^{\mathrm{R}}\right)$ is related to the number of vacancies posted, in the following way:

$1-F\left(X^{R}\right)=\lambda v^{\delta}$

where $\delta \geq 0$ and $\lambda>0$ are parameters to be estimated. In this case, the estimated coefficients, denoted by $\hat{\gamma}$, as shown in Tables 3 and 4, conflate the true $\gamma$ and $\delta$. In fact: $\hat{\gamma}=\gamma-\delta$, hence $\hat{\gamma}$ is downward biased if $\delta$ is strictly positive.

Our theoretical analysis indicates that given sequential search, $\gamma=1$, and given nonsequential search, $\gamma<1$. Hence, if $\hat{\gamma}=1$, then it is plausible that $\gamma=1$ and $\delta=0$. Therefore, when $\hat{\gamma}=1$, the above conclusion - that we cannot reject the hypothesis of sequential search - is not affected. When $\hat{\gamma}<1$, however, there is the possibility that $\gamma=1$ and $\delta>0$. This would imply sequential search, combined with decreasing returns-to-vacancies in the matching technology. Given the above empirical results, this possibility is relevant for three search methods only (advertisements, and the public and private employment agencies). While one cannot rule out this possibility completely, a matching technology with constant returns-to-scale can be established for all other search methods (seven search methods), and is consistent with Van Ours and Ridder (1991), so it is likely also valid for these search methods, too. ${ }^{41}$

To examine the effect of the number of vacancies on the (reservation) productivity level, we have applied a productivity-independency test. The test is based on the idea that the educational level of the applicant is a strong indicator of productivity (in large with the large human capital literature). If it is true that the reservation productivity depends negatively on

\footnotetext{
${ }^{40}$ We exclude the case of increasing returns-to-scale in the matching technology, because there seems little reason that this may occur.

${ }^{41}$ One may argue that search methods differ with respect to the number of applicants, and that the relationship between the arrival rate and the change in the productivity level depends on the number of applicants. Nevertheless, Table 2 shows that the average number of applicants per vacancy for the public employment office follows closely that of the internal recruitment method, so it remains difficult to explain why the matching technology of the former would exhibit decreasing returns-toscale while that of the latter is characterized by constant returns-to-scale. Furthermore, suppose that a given recruitment method is characterized by decreasing returns-to-scale (the number of applicants increases proportionally less than the number of vacancies posted), then firms are likely to counter the fall in the rate of arrival of applicants by activating additional recruitment methods. This is in line with evidence that the number of recruitment methods increases with the number of vacancies posted (Russo et al., 2000).
} 
the number of vacancies, which may have biased the above results, then the average productivity level of the accepted applicants must negatively depend on the number of vacancies. ${ }^{42}$ We have therefore estimated regression models where the dependent variable is the difference between the average educational level of the accepted applicants and the educational level required. ${ }^{43}$ We do not find any evidence of a positive effect of number of vacancies on this measure of productivity. In fact, we find even a slight negative effect, suggesting that our test is slightly conservative. This result is independent of whether we instrumented the number of vacancies. Furthermore, we have applied the same test on a subsample containing the three non-sequential search methods and a subsample containing the seven sequential search methods and we have distinguished by level of education. Again, there is no evidence that the number of vacancies positively affects this measure of productivity. $^{44}$

Suppose, nevertheless, that the number of vacancies affects productivity in other (unobservable) ways, so one may argue that the above tests have their limitations as they as assume a narrow definition of productivity. Further, suppose that the rejection of sequential search for three search methods is solely driven by changes in the reservation productivity (due to decreasing returns-to-scale of the firms' matching technology). The implied fall in the reservation productivity, given sequential search, is then implausibly large. Our results for $\hat{\gamma}$ (about 0.6 ) would imply $\delta=0.4$, and the probability of accepting an applicant increases by about 32\% when the number of vacancies increases from one to two. This implies that the average productivity of the accepted applicants when two vacancies are filled is much lower than the productivity level of the accepted applicant in the case of one vacancy. This seems implausible and is also inconsistent with our productivity independence tests. In conclusion, although it is theoretically possible that we reject sequential search too often if decreasing returns-to-vacancies are not controlled for, all the evidence supports the assumption of

\footnotetext{
${ }^{42}$ Note that we control for a large number of variables in the previous analysis which makes this type of bias not so likely. In particular, we already control for minimum educational requirements.

${ }^{43}$ To calculate the average level, we assume that educational level required is a ordinal number. Further, the test implicitly assumes that the variance of the educational level of the applicants is not relevant for the employer, so it is sufficient to focus on the average level of the accepted applicants. As we have few observations where the level of some of the accepted applicants exceeds, whereas for others is below the education required, the latter assumption is not important. Given these assumptions, the dependent variable of interest is the difference between the average educational level of the accepted applicants and the educational level required. Note that the information about the educational level of the applicants is less accurate if the number of accepted applicants increase, so we focus on observations where the number of vacancies is less than or equal to four, which covers most of the observations.

${ }^{44}$ Full results can be received upon request.
} 
constant returns-to-scale at the level of the firm, so the consequences for our tests are likely to be minor, given the current set of estimates, and more likely has no consequences at all.

\section{Conclusion}

In the current paper, we test whether firms search sequentially or non-sequentially for job applicants, and we argue that the incidence of these types of search behaviours is likely strongly-related to the type of search method used. Information about firms' search behaviour is not only useful for the proper modelling of the labour market, but may also be useful to understand whether the increasing number of studies which emphasise negative externalities of non-sequential search behaviour deal with a potentially important issue.

This paper analyzed a large dataset compiled of filled vacancies in order to test whether the chosen search method determines whether firms search sequentially or nonsequentially. This test is based on the relationship between the number of applicants and the number of filled vacancies. ${ }^{45}$ We do not reject the hypothesis of sequential search when firms use informal search methods, such as the use of social networks, and also for temporary employment agencies or school recruitment. However, we reject the null hypothesis of sequential search when firms use advertisements, or public and private employment agencies. The incidence of non-sequential methods is rather high in the Netherlands, covering about $45 \%$ of the filled vacancies. Since non-sequential search methods attract an above-average number of applicants (this applies to advertising, in particular), it is plausible that the number of job seekers who are confronted with non-sequential search by firms is substantially higher. Hence, although only three (out of ten) search methods appear to support a non-sequential search strategy, these cover a substantial part of the vacancies and therefore of job applicants. This makes it plausible, indeed, that many job seekers would respond to firms' non-sequential search procedures by adopting a non-sequential search strategy themselves, as argued by Morgan and Manning, 1985; Black and Loewenstein, 2002; Gautier, 2002.

Our interpretation of the results squares well with other studies that used more indirect evidence based on vacancy durations. Van Ours and Ridder (1992, 1993) suggest that the predominant use of advertising in the Dutch labour market may explain their conclusion that Dutch employers search non-sequentially. Abbring and Van Ours (1994) also conclude that employers search non-sequentially, when analysing information from the public employment

\footnotetext{
${ }^{45}$ The simple procedure illustrated here is quite general and it can potentially be used to test for sequential or non-sequential search in markets where multiple (identical) items are purchased and the
} 
office (but, see Andrews et al., 2008, for the U.K.). Our results indicate, therefore, that nonsequential search is an important feature of firm recruitment procedures, at least in the Netherlands. Nevertheless, it also suggests that in countries where the use of advertising and a public employment office are less common (e.g., Italy), non-sequential search by firms is likely relatively rare. Moreover, our empirical results imply that the firms' search method used conveys useful information about the search strategy of firms, in keeping with the results of DeVaro (2005), for example.

In the introduction, we argued that it is common in the literature to assume that firms search sequentially, although a limited number of studies have explored the consequences of non-sequential search. Our study, applied to the Netherlands, shows that the firms' sequential search assumption indeed holds for about $45 \%$ of the vacancies, whereas the proportion of job applicants who are involved in a non-sequential search process is likely higher. This implies that firm non-sequential search is a quantitatively important phenomenon. Introducing nonsequential search for a proportion of vacancies may therefore be a useful approach in the structural search model literature. Furthermore, our paper warrants the conclusion by a number of recent theoretical studies that negative externalities of non-sequential search may be an important issue (e.g., Albrecht et al., 2003). Our findings are also consistent with the stock-flow literature which suggests that job queues are an important element of the matching process.

price and the quality of the item is not affected by the number of items sought (see, also, Zwick et al., 2003). 


\section{References}

Abbring, J.H. and J.C. Van Ours (1994), Sequential or non-sequential employers' search?, Economics Letters, 44, 323-328.

Akerlof, G.A. (1981), Jobs as dam sites, The Review of Economic Studies, 48, 37-49.

Albrecht, J., P.A. Gautier and S. Vroman (2003), Matching with multiple applications, Economic Letters, 78, 67-70.

Albrecht, J., P.A. Gautier and S. Vroman (2006), Equilibrium directed search with multiple applications, The Review of Economic Studies, 73, 869-891.

Andrews, M.J., S. Bradley, D. Stott and R. Upward (2008), Successful employer search? An empirical analysis of vacancy duration using micro data, Economica, 75, 299, 455-480

Barron, J.M. and J. Bishop (1985), Extensive search, intensive search and hiring costs: new evidence on employer hiring activity, Economic Inquiry, 23, 363-382.

Barron, J.M., J. Bishop and W.C. Dunkelberg (1985), Employers' search: the interviewing and hiring of new employees, Review of Economics and Statistics, 67, 43-52.

Black, D.A. and M.A. Loewenstein (2002), Search, bargaining and the business cycle, in Search theory and unemployment, ed. S.A. Woodbury and C. Davidson, Springer, Chapter 3, 45-68

Burda, M.C. and S. Profit (1996), Matching across space: evidence on mobility in the Czech Republic, Labour Economics, 3, 255-278.

Burdett, K. and D.T. Mortensen (1998), Wage differentials, employer size, and unemployment, International Economic Review, 39, 2, 257-293.

Burdett, K. and E.J. Cunningham (1998), Toward a theory of vacancies, Journal of Labor Economics, 16, 445-478.

Burrows, P.M. (1972), Expected selection differentials for directional selection, Biometrics, 28, 1091-1100.

Cahuc, P., F. Postel-Vinay and J.M. Robin (2006), Wage bargaining with on-the-job search: theory and evidence, Econometrica, 2, 323-364.

Cameron C. and P. Trivedi (1998), Regression analysis of count data, Cambridge University Press.

Coles, M.G. and E. Smith (1998), Marketplaces and matching, Institutional Economic Review, 39, 1, 239-254.

Coles, M.G. and A. Muthoo (1998), Strategic bargaining and competitive bidding in a dynamic market equilibrium, Review of Economic Studies, 65, 235-260. 
Coles, M.G. (1999), Turnover externalities with marketplace trading, International Economic Review, 40, 4, 851-868.

Coles, M.G. and B. Petrongolo (2008), A test between unemployment theories and matching data, International Economic Review, forthcoming.

David, H.A. (1981), Order Statistics, second edition, Wiley \& Sons, New York.

DeVaro, J. (2005), Employer recruitment strategies and the labor market outcomes of new hires, Economic Inquiry, 43, 2, 263-282.

Devine, T. with J. Kiefer (1993), The empirical status of job search theory, Labour Economics, 1, 3-24.

Gautier, P.A. (2002), Non-sequential search, screening externalities and the public good role of recruitment offices, Economic Modelling, 19, 179-196.

HDFR (1998), How Do Firms Recruit? 1991-1998 (Hoe werven bedrijven?) 1991-1998, Intomart B.V, Hilversum, the Netherlands

Hilbe, J.M. (2007), Negative binomial Regression, Cambridge University Press, Cambridge, UK.

Hosios, A. (1990), On the efficiency of matching and related models of search and unemployment, Review of Economic Studies, 57, 279-298.

Lang, K. and S. Majumdar (2004), The pricing of job characteristics when markets do no is $t$ clear: theory and policy implications, International Economic Review, 45, 4, 1111-1128.

McKenna, C.J. (1985), Uncertainty and the labour market: recent developments in job-search theory, Harvester Press.

Montgomery, J. D. (1992), Job search and network composition: implications of the strengthof-weak-ties hypothesis, American Sociological Review, 57, 586-596.

Mood, A.M., F.A. Graybill and D.C. Boes (1974), Introduction To The Theory Of Statistics, McGraw-Hill.

Morgan, P.B. (1983), Search and optimal sample sizes, Review of Economic Studies, 659-675.

Morgan, P. and R. Manning (1985), Optimal search, Econometrica, 53, 923-944.

Mortensen, D.T. (2003), Wage Dispersion: Why Are Similar Workers Paid Differently? Cambridge, Massachusetts.

Pissarides, C.A. (2000), Equilibrium Unemployment Theory, MIT Press, second edition, Cambridge.

Rees, A. (1966), Information networks in labor markets, American Economic Review, 56, 559-566. 
Roper, S. (1988), Recruitment methods and vacancy durations, Scottish Journal of Political Economy, 35, 51-64.

Russo G., P. Rietveld, P. Nijkamp and C. Gorter (2000), Recruitment channel use and applicant arrival: an empirical analysis, Empirical Economics, 25, 673-697.

Russo, G., W.J. Hassink and C. Gorter (2005), Filling vacancies: an empirical analysis of the cost and benefit from search in the labor market, Applied Economics, 37, 1597-1606.

Rynes, S.L., R.D. Bretz and B. Gerhart (1991), The importance of recruitment in job choice, Personnel Psychology, 44, 487-521.

Stigler, G. (1961), The economics of information, Journal of Political Economy, 69, 213-225.

Van den Berg, G.J. and G. Ridder (1998), An empirical equilibrium search model of the labor market, Econometrica, 5, 1183-1221.

Van Ours, J.C. and G. Ridder (1991), Job requirements and the recruitment of new employees, Economic Letters, 36, 213-218.

Van Ours, J.C. and G. Ridder (1992), Vacancies and the recruitment of new employees, Journal of Labor Economics, 10, 138-155.

Van Ours, J.C. and G. Ridder (1993), Vacancy durations: search or selection? Oxford Bulletin of Economics and Statistics, 55, 187-198.

Winkelmann, R. (2003), Econometric analysis of count data, fourth edition, Springer.

Zwick, R., A. Rapoport, A. King Chung Lo and A.V. Muthukrishnan (2003), Consumer sequential search: not enough or too much? Marketing Science, 22, 503-519. 
Table 1: Search method use (\%)

$\begin{array}{lcccc} & \begin{array}{c}\text { Recruitment } \\ \text { action }\end{array} & \begin{array}{c}\text { Recruitment } \\ \text { action }\end{array} & \text { Vacancies } & \text { Applications } \\ \text { Informal Search Methods } & (1) & (2) & (3) & (4) \\ \text { Internal Search } & 9.38 & 8.29 & 7.65 & 3.11 \\ \text { Via Own Personnel } & 6.95 & 6.92 & 6.49 & 1.97 \\ \text { Business Relations } & 6.27 & 6.97 & 4.55 & 1.54 \\ \text { Walk-Ins } & 13.63 & 15.03 & 18.61 & 7.68 \\ \text { Formal Search Methods } & & & & \\ \text { Advertisements } & 28.00 & 29.44 & 31.93 & 68.49 \\ \text { Temporary Empl. Agency } & 10.57 & 10.53 & 9.92 & 4.1 \\ \text { Public Employment Agency } & 14.31 & 12.59 & 11.47 & 6.81 \\ \text { School Search } & 2.93 & 3.15 & 2.65 & 0.95 \\ \text { Private Employment Agency } & 2.69 & 3.00 & 2.07 & 3.16 \\ \text { Other Search Method } & 5.27 & 4.08 & 4.66 & 2.19 \\ & & & & \\ \text { Total } & 100 & 100 & 100 & 100 \\ \text { Number of Observations } & 39,814 & 32,546 & 70,730 & 450,858\end{array}$

Note: the first column is based on all observations. The last three columns are based on hiring activities that use only one search method. 
Table 2: Average number of applicants per vacancy

\begin{tabular}{lccccc} 
& \multicolumn{7}{c}{ Number of Vacancies Filled } & \\
Informal Search Methods & 1 & 2 & 3 & 4 & Whole Sample \\
Internal Search & 6.77 & 4.98 & 4.14 & 3.37 & 5.80 \\
Via Own Personnel & 3.21 & 2.88 & 2.82 & 2.17 & 3.02 \\
Business Relations & 2.75 & 2.44 & 1.94 & 1.82 & 2.65 \\
Walk-Ins & 3.05 & 2.93 & 3.52 & 3.18 & 3.03 \\
Formal Search Methods & & & & & \\
Advertisements & 26.99 & 14.89 & 10.89 & 10.28 & 20.73 \\
Temporary Employment Agency & 4.66 & 3.99 & 3.13 & 2.61 & 4.14 \\
Public Employment Agency & 7.25 & 4.52 & 4.07 & 3.77 & 5.94 \\
School Search & 2.68 & 2.45 & 3.11 & 3.51 & 2.71 \\
Private Employment Agency & 12.87 & 8.71 & 5.31 & 5.29 & 11.46 \\
Other Search Method & 4.29 & 3.81 & 3.82 & 2.27 & 4.00 \\
& & & & & \\
Mean Applicant per Vacancy & 11.11 & 7.07 & 5.63 & 5.06 & 9.02 \\
Number of Observations & & & & & 39,814
\end{tabular}


Table 3: Negative binomial regression model: number of rejected applicants by search method

\begin{tabular}{|c|c|c|c|c|c|}
\hline & Internal & $\begin{array}{l}\text { Via Own } \\
\text { Personnel }\end{array}$ & $\begin{array}{l}\text { Via Business } \\
\text { Relations }\end{array}$ & Walk-ins & Ads. \\
\hline Log Number of Vacancies & $\begin{array}{c}0.884 \\
(0.044)^{\star}\end{array}$ & $\begin{array}{l}1.048 \\
(0.063)\end{array}$ & $\begin{array}{c}0.922 \\
(0.088)\end{array}$ & $\begin{array}{c}0.950 \\
(0.041)\end{array}$ & $\begin{array}{c}0.603 \\
(0.016)^{*}\end{array}$ \\
\hline \multicolumn{6}{|l|}{ Educational Requirements } \\
\hline University & $\begin{array}{c}0.585 \\
(0.260)^{*}\end{array}$ & $\begin{array}{c}0.506 \\
(0.300)\end{array}$ & $\begin{array}{c}0.933 \\
(0.309)^{\star}\end{array}$ & $\begin{array}{c}0.288 \\
(0.221)\end{array}$ & $\begin{array}{c}0.412 \\
(0.055)^{\star}\end{array}$ \\
\hline Upper Vocational & $\begin{array}{c}0.486 \\
(0.184)^{\star}\end{array}$ & $\begin{array}{c}0.701 \\
(0.206)^{\star}\end{array}$ & $\begin{array}{c}0.858 \\
(0.234)^{*}\end{array}$ & $\begin{array}{c}0.229 \\
(0.145)\end{array}$ & $\begin{array}{c}0.407 \\
(0.043)^{*}\end{array}$ \\
\hline Upper Secondary General & $\begin{array}{c}0.585 \\
(0.205)^{\star}\end{array}$ & $\begin{array}{c}0.255 \\
(0.232)\end{array}$ & $\begin{array}{c}0.224 \\
(0.325)\end{array}$ & $\begin{array}{c}0.245 \\
(0.164)\end{array}$ & $\begin{array}{c}0.422 \\
(0.048)^{*}\end{array}$ \\
\hline Secondary Vocational & $\begin{array}{c}0.611 \\
(0.172)^{*}\end{array}$ & $\begin{array}{c}0.669 \\
(0.169)^{*}\end{array}$ & $\begin{array}{c}0.516 \\
(0.212)^{*}\end{array}$ & $\begin{array}{l}-0.012 \\
(0.111)\end{array}$ & $\begin{array}{c}0.292 \\
(0.040)^{*}\end{array}$ \\
\hline Secondary Genearal & $\begin{array}{c}0.201 \\
(0.197)\end{array}$ & $\begin{array}{c}0.481 \\
(0.194)^{\star}\end{array}$ & $\begin{array}{c}0.588 \\
(0.263)^{\star}\end{array}$ & $\begin{array}{c}0.424 \\
(0.119)^{\star}\end{array}$ & $\begin{array}{c}0.257 \\
(0.048)^{\star}\end{array}$ \\
\hline Primary Vocational & $\begin{array}{c}0.289 \\
(0.171)\end{array}$ & $\begin{array}{c}0.090 \\
(0.146)\end{array}$ & $\begin{array}{c}0.414 \\
(0.213)\end{array}$ & $\begin{array}{c}0.005 \\
(0.097)\end{array}$ & $\begin{array}{l}-0.017 \\
(0.042)\end{array}$ \\
\hline \multicolumn{6}{|l|}{ Vacancy Characteristics } \\
\hline Part Time & $\begin{array}{c}-0.422 \\
(0.091)^{\star}\end{array}$ & $\begin{array}{l}-0.172 \\
(0.112)\end{array}$ & $\begin{array}{l}-0.335 \\
(0.159)^{\star}\end{array}$ & $\begin{array}{c}-0.185 \\
(0.078)^{\star}\end{array}$ & $\begin{array}{c}-0.111 \\
(0.027)^{\star}\end{array}$ \\
\hline Permanent & $\begin{array}{c}0.257 \\
(0.073)^{\star}\end{array}$ & $\begin{array}{c}0.306 \\
(0.101)^{\star}\end{array}$ & $\begin{array}{c}0.247 \\
(0.129)\end{array}$ & $\begin{array}{c}0.101 \\
(0.066)\end{array}$ & $\begin{array}{c}0.091 \\
(0.026)^{*}\end{array}$ \\
\hline Experience Required & $\begin{array}{l}-0.146 \\
(0.080)\end{array}$ & $\begin{array}{c}0.150 \\
(0.097)\end{array}$ & $\begin{array}{c}0.093 \\
(0.142)\end{array}$ & $\begin{array}{c}0.126 \\
(0.065)\end{array}$ & $\begin{array}{c}0.041 \\
(0.020)^{*}\end{array}$ \\
\hline Age Limits & $\begin{array}{c}0.396 \\
(0.102)^{\star}\end{array}$ & $\begin{array}{c}0.685 \\
(0.122)^{\star}\end{array}$ & $\begin{array}{c}0.404 \\
(0.135)^{*}\end{array}$ & $\begin{array}{c}0.443 \\
(0.073)^{\star}\end{array}$ & $\begin{array}{c}0.109 \\
(0.019)^{*}\end{array}$ \\
\hline Log Number of Employees & $\begin{array}{c}0.231 \\
(0.025)^{\star}\end{array}$ & $\begin{array}{c}0.253 \\
(0.033)^{\star}\end{array}$ & $\begin{array}{c}0.165 \\
(0.037)^{\star}\end{array}$ & $\begin{array}{c}0.182 \\
(0.024)^{*}\end{array}$ & $\begin{array}{c}0.053 \\
(0.006)^{\star}\end{array}$ \\
\hline \multicolumn{6}{|l|}{ Business Cycle } \\
\hline Log Vacancies/Employment & $\begin{array}{c}0.020 \\
(0.109)\end{array}$ & $\begin{array}{l}-0.257 \\
(0.155)\end{array}$ & $\begin{array}{c}0.037 \\
(0.175)\end{array}$ & $\begin{array}{c}0.004 \\
(0.110)\end{array}$ & $\begin{array}{c}-0.080 \\
(0.030)^{*}\end{array}$ \\
\hline Log Unemployment Rate & $\begin{array}{c}0.040 \\
(0.292)\end{array}$ & $\begin{array}{l}-0.230 \\
(0.388)\end{array}$ & $\begin{array}{c}0.062 \\
(0.475)\end{array}$ & $\begin{array}{c}0.102 \\
(0.286)\end{array}$ & $\begin{array}{c}0.211 \\
(0.078)^{*}\end{array}$ \\
\hline Yearly Dummies $(7)^{\star}$ & Yes & Yes & Yes & Yes & Yes \\
\hline Occupational Dummies (8)* & Yes & Yes & Yes & Yes & Yes \\
\hline Industry Dummies (8)* & Yes & Yes & Yes & Yes & Yes \\
\hline Constant & $\begin{array}{l}-1.162 \\
(0.630)\end{array}$ & $\begin{array}{c}1.527 \\
(0.797)^{\star}\end{array}$ & $\begin{array}{l}-1.422 \\
(0.978)\end{array}$ & $\begin{array}{c}-1.511 \\
(0.045)^{\star}\end{array}$ & $\begin{array}{c}-0.399 \\
(0.022)^{\star}\end{array}$ \\
\hline \\
\hline Log Number of Vacancies & $\begin{array}{l}-0.072 \\
(0.042)\end{array}$ & $\begin{array}{c}0.035 \\
(0.053)\end{array}$ & $\begin{array}{c}0.272 \\
(0.091)^{*}\end{array}$ & $\begin{array}{c}0.166 \\
(0.036)^{\star}\end{array}$ & $\begin{array}{c}-0.436 \\
(0.021)^{*}\end{array}$ \\
\hline Constant & $\begin{array}{c}0.984 \\
(0.046)^{\star}\end{array}$ & $\begin{array}{c}-1.790 \\
(0.062)^{\star}\end{array}$ & $\begin{array}{c}1.842 \\
(0.065)^{\star}\end{array}$ & $\begin{array}{c}1.536 \\
(0.586)^{\star}\end{array}$ & $\begin{array}{c}1.125 \\
(0.162)^{*}\end{array}$ \\
\hline L. L. Restricted Model & -7879.38 & -4314.61 & -3165.33 & -10312.67 & -41581.99 \\
\hline L. L. Full Model & -7431.09 & -4015.31 & -3027.57 & -9530.61 & -39548.06 \\
\hline Chi Square Test (37) & 896.59 & 598.61 & 275.53 & 1564.11 & 4067.86 \\
\hline Number of Observations & 3734 & 2766 & 2496 & 5426 & 11147 \\
\hline
\end{tabular}


Table 3: Continued

\begin{tabular}{|c|c|c|c|c|c|}
\hline Log Number of Vacancies & $\begin{array}{c}\text { Temporary } \\
\text { Employment } \\
\text { Agency } \\
0.968 \\
(0.049)\end{array}$ & $\begin{array}{c}\text { Public } \\
\text { Employment } \\
\text { Agency } \\
0.677 \\
(0.031)^{\star}\end{array}$ & $\begin{array}{c}\text { School } \\
\text { Recruitment } \\
0.867 \\
(0.091)\end{array}$ & $\begin{array}{l}\text { Private } \\
\text { Employment } \\
\text { Agency } \\
0.568 \\
(0.088)^{\star}\end{array}$ & $\begin{array}{c}\text { Other } \\
\text { Recruitment } \\
\text { Methods } \\
0.961 \\
(0.074)\end{array}$ \\
\hline \multicolumn{6}{|l|}{ Educational Requirements } \\
\hline University & $\begin{array}{c}0.649 \\
(0.277)^{\star}\end{array}$ & $\begin{array}{c}0.027 \\
(0.217)\end{array}$ & $\begin{array}{c}0.393 \\
(0.593)\end{array}$ & $\begin{array}{c}0.193 \\
(0.333)\end{array}$ & $\begin{array}{c}0.510 \\
(0.273)\end{array}$ \\
\hline Upper Vocational & $\begin{array}{c}0.815 \\
(0.165)^{\star}\end{array}$ & $\begin{array}{c}0.064 \\
(0.095)\end{array}$ & $\begin{array}{c}0.130 \\
(0.436)\end{array}$ & $\begin{array}{c}0.300 \\
(0.294)\end{array}$ & $\begin{array}{c}0.444 \\
(0.230)\end{array}$ \\
\hline Secondary General & $\begin{array}{c}0.756 \\
(0.167)^{\star}\end{array}$ & $\begin{array}{c}0.030 \\
(0.095)\end{array}$ & $\begin{array}{c}0.185 \\
(0.532)\end{array}$ & $\begin{array}{c}0.582 \\
(0.351)\end{array}$ & $\begin{array}{c}0.378 \\
(0.285)\end{array}$ \\
\hline Secondary Vocational & $\begin{array}{c}0.694 \\
(0.147)^{\star}\end{array}$ & $\begin{array}{c}0.181 \\
(0.069)^{\star}\end{array}$ & $\begin{array}{l}-0.071 \\
(0.414)\end{array}$ & $\begin{array}{c}0.429 \\
(0.294)\end{array}$ & $\begin{array}{c}0.312 \\
(0.207)\end{array}$ \\
\hline Lower Secondary General & $\begin{array}{c}0.456 \\
(0.161)^{*}\end{array}$ & $\begin{array}{c}0.133 \\
(0.076)\end{array}$ & $\begin{array}{l}-0.206 \\
(0.444)\end{array}$ & $\begin{array}{c}0.157 \\
(0.338)\end{array}$ & $\begin{array}{c}0.245 \\
(0.210)\end{array}$ \\
\hline Primary Vocational & $\begin{array}{c}0.232 \\
(0.139)\end{array}$ & $\begin{array}{l}-0.049 \\
(0.062)\end{array}$ & $\begin{array}{l}-0.019 \\
(0.413)\end{array}$ & $\begin{array}{c}0.162 \\
(0.350)\end{array}$ & $\begin{array}{c}0.050 \\
(0.183)\end{array}$ \\
\hline \multicolumn{6}{|l|}{ Vacancy Characteristics } \\
\hline Part Time & $\begin{array}{c}-0.295 \\
(0.105)^{\star}\end{array}$ & $\begin{array}{c}-0.127 \\
(0.051)^{\star}\end{array}$ & $\begin{array}{l}-0.083 \\
(0.191)\end{array}$ & $\begin{array}{c}-0.388 \\
(0.158)^{\star}\end{array}$ & $\begin{array}{c}0.120 \\
(0.121)\end{array}$ \\
\hline Permanent & $\begin{array}{c}0.431 \\
(0.069)^{*}\end{array}$ & $\begin{array}{c}0.271 \\
(0.042)^{*}\end{array}$ & $\begin{array}{c}0.041 \\
(0.146)\end{array}$ & $\begin{array}{c}0.826 \\
(0.153)^{\star}\end{array}$ & $\begin{array}{c}0.320 \\
(0.114)^{\star}\end{array}$ \\
\hline Experience Required & $\begin{array}{c}0.082 \\
(0.059)\end{array}$ & $\begin{array}{c}0.074 \\
(0.037)^{\star}\end{array}$ & $\begin{array}{c}0.227 \\
(0.138)\end{array}$ & $\begin{array}{l}-0.122 \\
(0.142)\end{array}$ & $\begin{array}{l}-0.159 \\
(0.109)\end{array}$ \\
\hline Age Limits & $\begin{array}{c}0.332 \\
(0.059)^{\star}\end{array}$ & $\begin{array}{c}0.162 \\
(0.041)^{*}\end{array}$ & $\begin{array}{c}0.573 \\
(0.143)^{\star}\end{array}$ & $\begin{array}{c}0.429 \\
(0.083)^{\star}\end{array}$ & $\begin{array}{c}0.508 \\
(0.123)^{\star}\end{array}$ \\
\hline Log Number of Employees & $\begin{array}{c}0.015 \\
(0.022)\end{array}$ & $\begin{array}{c}0.054 \\
(0.014)^{\star}\end{array}$ & $\begin{array}{c}0.180 \\
(0.049)^{\star}\end{array}$ & $\begin{array}{c}0.109 \\
(0.033)^{\star}\end{array}$ & $\begin{array}{c}0.130 \\
(0.037)^{\star}\end{array}$ \\
\hline \multicolumn{6}{|l|}{ Business Cycle } \\
\hline Log Vacancies/Employment & $\begin{array}{c}0.090 \\
(0.099)\end{array}$ & $\begin{array}{c}0.152 \\
(0.063)^{\star}\end{array}$ & $\begin{array}{c}0.136 \\
(0.253)\end{array}$ & $\begin{array}{l}-0.243 \\
(0.137)\end{array}$ & $\begin{array}{l}-0.072 \\
(0.179)\end{array}$ \\
\hline Log Unemployment Rate & $\begin{array}{l}-0.010 \\
(0.258)\end{array}$ & $\begin{array}{c}0.059 \\
(0.175)\end{array}$ & $\begin{array}{l}-0.263 \\
(0.648)\end{array}$ & $\begin{array}{c}0.229 \\
(0.345)\end{array}$ & $\begin{array}{l}-0.661 \\
(0.441)\end{array}$ \\
\hline Yearly Dummies $(7)^{\star}$ & Yes & Yes & Yes & Yes & Yes \\
\hline Occupational Dummies (8)* & Yes & Yes & Yes & Yes & Yes \\
\hline Industry Dummies (8)* & Yes & Yes & Yes & Yes & Yes \\
\hline Constant & $\begin{array}{l}-0.663 \\
(0.044)^{\star}\end{array}$ & $\begin{array}{l}0.108 \\
(0.035)^{\star}\end{array}$ & $\begin{array}{l}-1.523 \\
(0.100)^{\star}\end{array}$ & $\begin{array}{l}-0.342 \\
(0.807)\end{array}$ & $\begin{array}{l}0.741 \\
(0.916)\end{array}$ \\
\hline \multicolumn{6}{|l|}{ Dispersion Parameter ( $\alpha$ ) } \\
\hline Log Number of Vacancies & $\begin{array}{c}-0.452 \\
(0.047)^{\star}\end{array}$ & $\begin{array}{c}-0.272 \\
(0.036)^{\star}\end{array}$ & $\begin{array}{c}0.180 \\
(0.104)\end{array}$ & $\begin{array}{c}-0.314 \\
(0.118)^{\star}\end{array}$ & $\begin{array}{c}0.021 \\
(0.055)\end{array}$ \\
\hline Constant & $\begin{array}{c}0.725 \\
(0.545)\end{array}$ & $\begin{array}{c}0.411 \\
(0.362)\end{array}$ & $\begin{array}{c}1.376 \\
(1.365)\end{array}$ & $\begin{array}{c}0.167 \\
(0.060)^{*}\end{array}$ & $\begin{array}{c}1.424 \\
(0.067)^{\star}\end{array}$ \\
\hline L. L. Restricted Model & -8785.11 & -14877.91 & -1953.31 & -3190.28 & -4161.07 \\
\hline L. L. Full Model & -8510.71 & -14162.47 & -1787.28 & -2971.22 & -3616.94 \\
\hline Chi Square Test (37) & 548.79 & 1430.88 & 332.05 & 438.12 & 1088.27 \\
\hline $\begin{array}{l}\text { Number of Observations } \\
\text { Note: Reference group of th } \\
\text { part-time (full-time), permar } \\
\text { (no age limits). Standard err }\end{array}$ & $\begin{array}{l}4208 \\
\text { ariables is i } \\
\text { t (temporary } \\
\text { in parenthe }\end{array}$ & $\begin{array}{l}5699 \\
\text { arentheses: } \\
\text { xperience } r\end{array}$ & $\begin{array}{l}1167 \\
\text { cational re } \\
\text { ed (no ex }\end{array}$ & $\begin{array}{l}1071 \\
\text { nents (prin } \\
\text { ce require }\end{array}$ & $\begin{array}{l}2100 \\
\text { general), } \\
\text { age limits } \\
\text { (evel). }\end{array}$ \\
\hline
\end{tabular}


Table 4: Robustness of the elasticity of the number of rejected applicants to the number of vacancies by search method. Negative binomial regression models, robust standard errors in parentheses, *: statistically different from one.

\begin{tabular}{|c|c|c|c|c|c|}
\hline & Internal & $\begin{array}{l}\text { Via Own } \\
\text { Personnel }\end{array}$ & $\begin{array}{c}\text { Via } \\
\text { Business } \\
\text { Relations }\end{array}$ & Walk-ins & Advertisements \\
\hline Original Model & $\begin{array}{c}0.884 \\
(0.044)^{*}\end{array}$ & $\begin{array}{c}1.048 \\
(0.063)\end{array}$ & $\begin{array}{c}0.922 \\
(0.088)\end{array}$ & $\begin{array}{c}0.950 \\
(0.041)\end{array}$ & $\begin{array}{c}0.603 \\
(0.016)^{*}\end{array}$ \\
\hline \multirow[t]{2}{*}{$\begin{array}{l}\text { Firms that hired during the } \\
\text { previous year (restricted sample) }\end{array}$} & 0.932 & 1.060 & 0.839 & 0.971 & 0.638 \\
\hline & $(0.053)$ & $(0.080)$ & $(0.118)$ & $(0.049)$ & $(0.020)^{\star}$ \\
\hline \multirow{3}{*}{$\begin{array}{l}\text { Inclusion of firms' intention to } \\
\text { hire }\end{array}$} & 0.871 & 1.062 & 0.925 & 0.953 & 0.605 \\
\hline & $(0.044)^{*}$ & $(0.063)$ & (0.088) & $(0.042)$ & $(0.016)^{*}$ \\
\hline & $\begin{array}{c}\text { Temporary } \\
\text { Employment } \\
\text { Agency }\end{array}$ & $\begin{array}{c}\text { Public } \\
\text { Employment } \\
\text { Agency }\end{array}$ & $\begin{array}{c}\text { School } \\
\text { Recruitment }\end{array}$ & $\begin{array}{l}\text { Private } \\
\text { Employment } \\
\text { Agency }\end{array}$ & $\begin{array}{c}\text { Other } \\
\text { Recruitment } \\
\text { Methods }\end{array}$ \\
\hline Original Model & $\begin{array}{c}0.968 \\
(0.049)\end{array}$ & $\begin{array}{c}0.677 \\
(0.031)^{*}\end{array}$ & $\begin{array}{c}0.867 \\
(0.091)\end{array}$ & $\begin{array}{c}0.568 \\
(0.088)^{*}\end{array}$ & $\begin{array}{c}0.961 \\
(0.074)\end{array}$ \\
\hline $\begin{array}{l}\text { Firms that hired during the } \\
\text { previous year (restricted sample) }\end{array}$ & 0.977 & 0.682 & 0.936 & 0.652 & 0.947 \\
\hline \multirow{3}{*}{$\begin{array}{l}\text { Inclusion of firms' intention to } \\
\text { hire }\end{array}$} & $(0.057)$ & $(0.038)^{*}$ & $(0.133)$ & $(0.108)^{\star}$ & $(0.082)$ \\
\hline & 0.955 & 0.682 & 0.872 & 0.557 & 0.964 \\
\hline & $(0.049)$ & $(0.031)^{*}$ & $(0.092)$ & $(0.089)^{*}$ & $(0.074)$ \\
\hline
\end{tabular}




\section{Appendix 1: Non-sequential search}

In the non-sequential search case, firms are assumed to fill $v$ vacancies during one search period. Firms gather a pool of $n$ applicants and hire the $v$ applicants with the highest productivity level $(n \geq v)$. Firms incur costs screening $n$ applicants. The size of the applicant pool is optimally chosen.

The value of $v$ open vacancies, $\mathrm{V}$, equals the sum of the cost to attract applicants and the expected gain from hiring the $v$ best applicants:

$$
V=-c n+\mathrm{E}\left(\sum_{i=1}^{v} X_{i}\right)
$$

where $c$ denotes the screening cost per applicant, $X_{i}$ is the net productivity (productivity net of the labour cost) of the hired applicant, $i$, and $\mathrm{E}$ is the expectation operator. The evaluation of the last element of the right-hand side of the above equation requires the use of order statistics (e.g., Mood et al. 1974).

The expected productivity of the best $v$ candidates can be written as

$$
E\left(\sum_{i=1}^{v} X_{i}\right)=\int_{-\infty}^{+\infty} \int_{-\infty}^{X_{v}} \ldots \int_{-\infty}^{X_{3}} \int_{-\infty}^{X_{2}}\left(X_{1}+\ldots+X_{v}\right) \frac{n !}{(n-v) !} F_{X_{1}}^{n-v} f_{X_{1}} \ldots f_{X_{v}} d X_{1} \ldots d X_{v},
$$

where $\mathrm{F}$ is the cumulative productivity distribution, $f$ denotes the corresponding probability distribution, and $\mathrm{X}$ is the (net) productivity. $\mathrm{X}_{\mathrm{v}}$ denotes the productivity level of the best applicant, $\mathrm{X}_{\mathrm{v}-1}$ denotes the productivity level of the second-best applicant, etc. Note that (A2) takes into account that the range of $X_{\mathrm{v}-1}$ is from $-\infty$ to $\mathrm{X}_{\mathrm{v}}$. The size of the pool of applicants is chosen by maximising (A1) with respect to $n$. The relationship between $n$ and $v$ is now more complicated than in the sequential search case.

\section{Uniform distribution}

Suppose that workers' productivity follows a uniform distribution on [0,1]. (A2) can then be simplified as follows:

$$
\begin{aligned}
& E\left(\sum_{i=1}^{v} X_{i}\right)=\frac{n !}{(n-v) !} \int_{0}^{1} \int_{0}^{X_{v}} \ldots \int_{0}^{X_{3} X_{2}}\left(X_{0}+\ldots+X_{1}\right) X_{1}^{n-v} d X_{1} \ldots d X_{v}= \\
& \frac{n}{n+1}+\frac{n-1}{n+1}+\frac{n-2}{n+1}+\ldots+\frac{n-v+1}{n+1}=v-\frac{1}{n+1} \frac{v(v+1)}{2} .
\end{aligned}
$$

We substitute equation (A3) into equation (A1) and, assuming that $n$ is continuous, the first-order condition for the optimal size of the applicant pool, $n$, is

$$
n=-1+\sqrt{\frac{v(v+1)}{2 c}}
$$


It is now straightforward to show that:

$$
\gamma=\partial \log n / \partial \log v=\frac{1}{2}(2 c)^{-0.5} \frac{2 v+1}{((v+1) v)^{0.5}} \frac{v}{-1+\sqrt{\frac{v(v+1)}{2 c}}}
$$

Rather obviously, $\gamma$ is not a constant equal to one. In fact, it can be easily shown that for reasonable low values for $c, \gamma<1$. It can be shown that the latter is true under the condition that $c \leq v /(8(v+1)) \leq 1 / 16=0.0625=6.25 \%$. Hence, $\gamma<1$ when $c$ is less than $6.25 \%$ of the net productivity. This condition is true for vacancies in the real world. ${ }^{46}$

For reasonably small values of $c$ (e.g. $c \leq 0.006)$, $\partial \log n / \partial \log v$ does not depend on $c$ and can be approximated as follows:

$$
\gamma=\partial \log n / \partial \log v \approx \frac{2 v+1}{2 v+2} .
$$

\section{Exponential distribution}

Suppose that workers' productivity follows an exponential distribution: $F(X)=e^{-X}, X \geq 0$. Then, it can be shown that $E\left(\sum_{i=1}^{v} X_{i}\right)=\sum_{i=1}^{n} \frac{1}{i}+\sum_{i=2}^{n} \frac{1}{i}+\ldots+\sum_{i=v}^{n} \frac{1}{i}$ (see David, 1981, p. 49). Hence, presuming that $n$ is continuous, the first-order condition of (A1) with respect to $n$ implies then that $-c+v / n=0$, so $\gamma=\partial \log n / \partial \log v=1$.

\footnotetext{
${ }^{46}$ For example, in the Netherlands, the average monetary search cost to fill one vacancy is about $3 \%$ of the yearly labour cost (Russo et al., 2005). Given that the expected employment duration is about seven years, and an average of nine applicants are screened per filled vacancy, the monetary cost per applicant relative to total labour cost is about $0.05 \%$. The time cost per applicant is estimated to be on the order of $0.02 \%$ (this estimate is based on the assumption that an interview by one recruiter takes about one hour). Presuming that net productivity is about 0.1 of the total labour cost, $c$ is about $0.7 \%$. The marginal cost $c$ is thus an order of magnitude smaller than $6.25 \%$.
} 
Appendix 2: Summary statistics

Variable

Log Number of Applicants

Log Number of Filled Vacancies

Educational Requirements

University

Upper Vocational

Secondary General

Secondary Vocational

Lower Secondary General

Primary Vocational

Primary General

Vacancy and Firm Characteristics

Part Time

Permanent

Experience Required

Age Limits

Log Number of Employees

Business Cycle

Log Vacancies/Employment (Regional)

Log Unemployment Rate (Regional)

1991

1992

1993

1994

1995

1996

1997

1998

\section{Occupation}

Scientific Personnel

Consultants

Managers

Administrative Personnel

Commercial Personnel

Service Personnel

Agricultural Workers

Supervisory and Production Personnel

Craftsmen

Industry

Agriculture ISBN 1

Mining ISBN 2

Manufacturing ISBN 3

Utilities ISBN 4

Construction ISBN 5

Trade and Restaurants/hotels ISBN 6

Transport and Communications ISBN 7

Financial and Business Services ISBN 8

Personal Services ISBN 9

Number of Observations
Mean Std. Dev. Min Max

$\begin{array}{llll}1.61 & 1.37 & 0.00 & 6.91\end{array}$

$\begin{array}{llll}0.48 & 0.74 & 0.00 & 5.97\end{array}$

$\begin{array}{llll}0.03 & 0.16 & 0.00 & 1.00\end{array}$

$\begin{array}{llll}0.18 & 0.39 & 0.00 & 1.00\end{array}$

$\begin{array}{llll}0.05 & 0.21 & 0.00 & 1.00\end{array}$

$\begin{array}{llll}0.28 & 0.45 & 0.00 & 1.00\end{array}$

$\begin{array}{llll}0.08 & 0.27 & 0.00 & 1.00\end{array}$

$\begin{array}{llll}0.27 & 0.44 & 0.00 & 1.00\end{array}$

$\begin{array}{llll}0.11 & 0.32 & 0.00 & 1.00\end{array}$

$\begin{array}{llll}0.18 & 0.37 & 0.00 & 1.00\end{array}$

$\begin{array}{llll}0.76 & 0.43 & 0.00 & 1.00\end{array}$

$\begin{array}{llll}0.64 & 0.48 & 0.00 & 1.00\end{array}$

$\begin{array}{llll}0.19 & 0.40 & 0.00 & 1.00\end{array}$

$\begin{array}{llll}3.89 & 1.51 & 0.69 & 9.10\end{array}$

$\begin{array}{llll}-0.13 & 0.48 & -1.23 & 0.99\end{array}$

$\begin{array}{llll}1.94 & 0.20 & 1.36 & 2.48\end{array}$

$\begin{array}{llll}0.09 & 0.28 & 0.00 & 1.00\end{array}$

$\begin{array}{llll}0.17 & 0.38 & 0.00 & 1.00\end{array}$

$\begin{array}{llll}0.15 & 0.36 & 0.00 & 1.00\end{array}$

$\begin{array}{llll}0.14 & 0.34 & 0.00 & 1.00\end{array}$

$\begin{array}{llll}0.13 & 0.33 & 0.00 & 1.00\end{array}$

$\begin{array}{llll}0.09 & 0.28 & 0.00 & 1.00\end{array}$

$\begin{array}{llll}0.14 & 0.35 & 0.00 & 1.00\end{array}$

$\begin{array}{llll}0.09 & 0.29 & 0.00 & 1.00\end{array}$

$\begin{array}{llll}0.10 & 0.30 & 0.00 & 1.00\end{array}$

$\begin{array}{llll}0.09 & 0.29 & 0.00 & 1.00\end{array}$

$\begin{array}{llll}0.03 & 0.17 & 0.00 & 1.00\end{array}$

$\begin{array}{llll}0.19 & 0.39 & 0.00 & 1.00\end{array}$

$\begin{array}{llll}0.11 & 0.31 & 0.00 & 1.00\end{array}$

$\begin{array}{llll}0.12 & 0.32 & 0.00 & 1.00\end{array}$

$\begin{array}{llll}0.02 & 0.14 & 0.00 & 1.00\end{array}$

$\begin{array}{llll}0.03 & 0.17 & 0.00 & 1.00\end{array}$

$\begin{array}{llll}0.11 & 0.32 & 0.00 & 1.00\end{array}$

$\begin{array}{llll}0.03 & 0.16 & 0.00 & 1.00\end{array}$

$\begin{array}{llll}0.09 & 0.29 & 0.00 & 1.00\end{array}$

$\begin{array}{llll}0.10 & 0.31 & 0.00 & 1.00\end{array}$

$\begin{array}{llll}0.00 & 0.06 & 0.00 & 1.00\end{array}$

$\begin{array}{llll}0.13 & 0.34 & 0.00 & 1.00\end{array}$

$\begin{array}{llll}0.20 & 0.40 & 0.00 & 1.00\end{array}$

$\begin{array}{llll}0.07 & 0.25 & 0.00 & 1.00\end{array}$

$\begin{array}{llll}0.11 & 0.31 & 0.00 & 1.00\end{array}$

$\begin{array}{llll}0.25 & 0.43 & 0.00 & 1.00\end{array}$

39,814 
Appendix 3: Incidence of search method by characteristic of hired worker (percentage)

Panel A: Educational Level

Primary General

Primary Vocational

Lower Secondary General

Secondary Vocational

Secondary General

Upper Vocational

University

Panel B: Previous Labour Market Position

Employed

Jobless

School-leaver

Panel C: Work Experience

With

Without

$\begin{array}{lc}\text { Advertisements } & \begin{array}{c}\text { Public } \\ \text { Employment } \\ \text { Agency }\end{array} \\ 19.52 & 17.74 \\ 24.94 & 16.76 \\ 28.38 & 16.23 \\ 31.81 & 12.31 \\ 29.44 & 10.19 \\ 33.41 & 13.11 \\ 37.61 & 7.20\end{array}$

32.38

22.52

26.30

28.80

30.19

Private
Agency
0.52
0.48
0.88
1.51
1.05
5.51
4.11

9.73

24.55

10.15

12.78

15.10

2.70

0.94

0.61

2.12

$\begin{array}{ccc}\begin{array}{c}\text { Non- } \\ \text { Sequential } \\ \text { Search }\end{array} & \begin{array}{c}\text { Sequential } \\ \text { Search }\end{array} & \text { Total } \\ 37.78 & 62.22 & 100 \\ 42.18 & 57.82 & 100 \\ 45.49 & 54.51 & 100 \\ 45.63 & 54.37 & 100 \\ 40.68 & 59.32 & 100 \\ 52.03 & 47.97 & 100 \\ 48.92 & 51.08 & 100\end{array}$

44.81

48.01

55.19

51.99

62.94

100

100

100

43.70

56.30

53.70

100 


\section{Appendix 4: Robustness of the results: alternative estimation methods}

We aim to test that the expected number of applicants $E(n)$ is proportional to the number of job openings $v$, so that $E(n)=\rho v$. Now, suppose the presence of random error that is multiplicative, so $n=\rho v \varepsilon$, where $\rho>0$ and $\varepsilon$ is random error with $E(\varepsilon)=1$. Then, the logarithm of the number of applicants is linked to the logarithm of the number of vacancies as follows:

$$
\log n=\log \rho+\log v+\log \varepsilon
$$

We have estimated (A1) using a standard regression analysis (OLS) approach.

\section{TABLE A1 ABOUT HERE}

In Table A1, we have compiled the estimated vacancy elasticity using OLS on the whole sample, using OLS on the restricted sample. These results support our conclusions drawn from the count models. Arguably, the above results may be biased since it is ignored that in the data must hold that $n \geq v$, so $\log n \geq \log v$. For the search methods with many applicants, such as advertising, $n>v$ for almost all observations, but for the search methods with few applicants, the number of applicants is frequently equal to the number of vacancies. One can easily deal with this issue by estimating left-censored regression (Tobit) models. The estimated vacancy elasticities based on this model are almost exactly equal to the results reported in Table A1. 
Table A1: Coefficient of the (log) number of filled vacancies on the (log) number of applicants by search method, regression analysis

$\begin{array}{lccccc}\text { (Log) Number of } & \text { Internal } & \begin{array}{c}\text { Via Own } \\ \text { Personnel }\end{array} & \begin{array}{c}\text { Via Business } \\ \text { Relations }\end{array} & \text { Walk-ins } & \text { Advertisements } \\ \text { Filled Vacancies } & & & & & \\ \text { Full Sample (OLS) } & 0.871 & 1.015 & 1.011 & 1.005 & 0.556 \\ & (0.025)^{\star} & (0.022) & (0.032) & (0.016) & (0.017)^{\star} \\ \text { Restricted Sample (OLS) } & 0.889 & 1.002 & 0.982 & 0.999 & 0.584 \\ & (0.030)^{\star} & (0.027) & (0.040) & (0.019) & (0.022)^{\star} \\ & & & & & \text { Other } \\ & \text { Temporary } & \text { Public } & & \text { Private } & \text { Search } \\ & \text { Work } & \text { Employment } & \text { School } & \text { Employment } & \text { Methods } \\ & \text { Agency } & \text { Agency } & \text { Search } & \text { Agency } & \\ & & & & & 0.972 \\ \text { Full Sample (OLS) } & 0.972 & 0.806 & 1.006 & 0.697 & (0.030) \\ & (0.022) & (0.020)^{\star} & (0.038) & (0.076)^{\star} & 0.957 \\ \text { Restricted Sample (OLS) } & 0.963 & 0.800 & 1.051 & 0.664 & (0.035)\end{array}$

Note: Robust standard error in parentheses (*: different from 1 at the $5 \%$ confidence level). 